\title{
Article \\ Predictors of Abdominal Aortic Aneurysm Shrinkage after Endovascular Repair
}

\author{
Rianne E. van Rijswijk ${ }^{1,2, * \mathbb{D}}$, Erik Groot Jebbink ${ }^{1,2}{ }^{\oplus}$, Suzanne Holewijn ${ }^{1}\left(\right.$, Nicky Stoop ${ }^{1}$, \\ Steven M. van Sterkenburg ${ }^{1}$ and Michel M. P. J. Reijnen ${ }^{1,2}$ (1) \\ 1 Department of Vascular Surgery, Rijnstate, 6815 AD Arnhem, The Netherlands; \\ e.grootjebbink@utwente.nl (E.G.J.); sholewijn@rijnstate.nl (S.H.); nickystoop@hotmail.com (N.S.); \\ svansterkenburg@rijnstate.nl (S.M.v.S.); mreijnen@rijnstate.nl (M.M.P.J.R.) \\ 2 Multi-Modality Medical Imaging Group, TechMed Centre, University of Twente, \\ 7522 NH Enschede, The Netherlands \\ * Correspondence: r.e.vanrijswijk@gmail.com
}

check for updates

Citation: van Rijswijk, R.E.; Groot Jebbink, E.; Holewijn, S.; Stoop, N.; van Sterkenburg, S.M.; Reijnen, M.M.P.J. Predictors of Abdominal Aortic Aneurysm Shrinkage after Endovascular Repair. J. Clin. Med. 2022, 11, 1394. https://doi.org/ $10.3390 / j \mathrm{~cm} 11051394$

Academic Editor: Kyriakos Oikonomou

Received: 26 January 2022 Accepted: 25 February 2022 Published: 3 March 2022

Publisher's Note: MDPI stays neutral with regard to jurisdictional claims in published maps and institutional affiliations.

Copyright: (c) 2022 by the authors. Licensee MDPI, Basel, Switzerland. This article is an open access article distributed under the terms and conditions of the Creative Commons Attribution (CC BY) license (https:// creativecommons.org/licenses/by/ $4.0 /)$.

\begin{abstract}
Recent studies demonstrate that patients with a shrinking abdominal aortic aneurysm (AAA), one-year after endovascular repair (EVAR), have better long-term outcomes than patients with a stable AAA. It is not known what factors determine whether an AAA will shrink or not. In this study, a range of parameters was investigated to identify their use in differentiating patients that will develop a shrinking AAA from those with a stable AAA one-year after EVAR. Hundredseventy-four patients (67 shrinking AAA, 107 stable AAA) who underwent elective, infrarenal EVAR were enrolled between 2011-2018. Long-term survival was significantly better in patients with a shrinking AAA, compared to those with a stable AAA $(p=0.038)$. Larger preoperative maximum AAA diameter was associated with an increased likelihood of developing AAA shrinkage one-year after EVAR-whereas older age and larger preoperative infrarenal $\beta$ angle were associated with a reduced likelihood of AAA shrinkage. However, this multivariate logistic regression model was only able to correctly identify $66.7 \%$ of patients with AAA shrinkage from the total cohort. This is not sufficient for implementation in clinical care, and therefore future research is recommended to dive deeper into AAA anatomy, and explore potential predictors using artificial intelligence and radiomics.
\end{abstract}

Keywords: AAA; EVAR; remodeling; shrinkage; regression; prediction

\section{Introduction}

An abdominal aortic aneurysm (AAA) eligible for treatment can be treated with either open surgical repair (OSR) or endovascular repair (EVAR). Because of its minimally invasive nature, EVAR has an early benefit with regard to morbidity and mortality in comparison to OSR [1,2]. However, long-term mortality and rupture risk of EVAR are increased compared to OSR [1,2].

In the case of EVAR, AAA growth is thought to represent treatment failure as it reflects pressure on the aneurysm wall-indicating the aneurysm is still at risk of rupture despite the intervention [3]. Several studies have shown that this growth is mostly related to the presence of endoleaks [4-6]. A stable or shrinking aneurysm diameter after EVAR has traditionally been considered a treatment success. However, recent studies indicate that patients with AAA shrinkage, at one-year after EVAR, have significantly better longterm outcomes compared to patients with growing AAA, but also to those with stable AAA [7-11]. These outcomes include fewer reinterventions and late complications, less rupture, and a lower all-cause mortality [7-11]. These observations were independent of the occurrence of endoleaks and reinterventions performed [7]. Therefore, the view is shifting from AAA growth as a predictor of EVAR failure, to AAA shrinkage as a predictor of EVAR success. 
However, as these advances are only recent, it is not yet known what causes one patient to develop a stable AAA while others have a shrinking AAA one-year after EVAR. Lalys et al. performed a systematic review and meta-analysis on predictors of AAA shrinkage, but they studied shrinkage at any time during follow-up and not specifically one-year after EVAR [12]. Furthermore, a recent systematic review of anatomical predictors of AAA remodeling showed that strong consistent evidence on this type of predictor is missing [13]. It is important though to identify predictors of AAA shrinkage since they also indirectly predict positive long-term outcomes after EVAR.

In this study, we therefore investigated a broad range of demographic, clinical, and procedural parameters to identify their potential in differentiating patients that will develop a shrinking AAA from patients who will have a stable AAA at one-year after EVAR. This paper shows that age, preoperative AAA diameter, and infrarenal angle are significantly associated with the development of AAA shrinkage. However, the multivariate logistic regression model was only able to correctly identify AAA shrinkage in $66.7 \%$ of the total patient group.

\section{Materials and Methods}

\subsection{Study Design and Patient Population}

A single-center, retrospective, observational study was performed on patients that were electively treated for an infrarenal AAA between 1 January 2011, and 31 December 2018, and had similar imaging available preoperatively and during follow-up. The regional Human Research Committee declared that the study was not subject to the Medical Research Involving Human Subjects Act (case number: 2020-6721). Approval for data collection and publication was granted by the institutional review board (study number: 2021-1836).

Patients were included if they underwent elective EVAR for an infrarenal AAA with initial assisted technical success - according to the reporting standards for EVAR [14]. Patients had to be treated with endografts that are still used in current clinical practice-including the Excluder (W.L. Gore and Associates, Flagstaff, AZ, USA), Endurant (Medtronic, Minneapolis, MN, USA), Zenith (Cook, Bloomington, IN, USA), Incraft (CardinalHealth, Dublin, Ireland), AFX (Endologix, Irvine, CA, USA), and Anaconda (Terumo Aortic, Inchinnan, UK) endografts. Follow-up data of at least one-year was required-including AAA imaging. Either computed tomography (CT)-CT or ultrasound (US)-US was used to compare the preoperative and postoperative AAA diameter. Patients with ruptured, inflammatory, symptomatic, juxtarenal, suprarenal, thoracoabdominal, and thoracal aneurysms were excluded, as well as patients treated with fenestrated or branched endografts, iliac branched devices, non-CE marked devices within a trial setting, or chimney procedures. Furthermore, patients with an AAA-related reintervention within one-year after EVAR were excluded, because both the complication and the reintervention might have influenced the state of AAA remodeling at one-year.

\subsection{Definitions and Data Collection}

Preoperative, perioperative, and early postoperative data were retrospectively derived from the electronic health records of the included patients and entered into an SPSS database (Version 22, IBM Corporation, Armonk, NY, USA). Preoperative neck and iliac vascular characteristics were extracted from the radiologist's reports of the preoperative CT scan. The preoperative infrarenal $\beta$ angle between the flow axis of the infrarenal neck and the body of the AAA $\left(^{\circ}\right)$ [15] was measured on the preoperative CT scan using IntelliSpace Portal (Version 11.1, Philips, Best, The Netherlands) for all included patients. The maximum AAA diameter $(\mathrm{mm})$ was also measured with this software on the preoperative and 12 (range 6-18) months postoperative CT scan for all included patients. The diameter was measured in the plane perpendicular to the aortic centerline-in the anterior-posterior direction-from the outer wall to the outer wall [16]. For every patient, two additional variables were computed-the Society for Vascular Surgery/American Association for 
Vascular Surgery (SVS/AAVS) medical comorbidity grading [15] and the St George's Vascular Institute (SGVI) risk score [17]. The SGVI score is based on the maximum AAA diameter and largest common iliac artery diameter and serves as a predictor of mid-term reinterventions and endograft complications [18].

The included patients were stratified into two groups based on the difference in maximum AAA diameter preoperative and one-year after EVAR. Because of known poor agreement in diameter measurement between CT and US imaging, pre- and postoperative diameters were only compared if they were measured with the same imaging modality [19]. All US assessments were performed by dedicated vascular technicians. The choice of imaging modality was per discretion of the treating surgeon. If patients had both US and CT imaging preoperatively and one-year after EVAR, the diameter difference on CT was used-except if the date of the postoperative CT was $\leq 9$ months or $\geq 15$ months after EVAR and the US date was within 10-14 months after EVAR. Patients with a postoperative diameter reduction of $\geq 5 \mathrm{~mm}$ were assigned to the shrinkage group, and patients with a diameter difference of $<5 \mathrm{~mm}$ were assigned to the stable group [14].

\subsection{Statistical Analysis}

Demographic, clinical, procedural, and early postoperative characteristics were presented as counts and percentages for categorical variables, and as means \pm standard deviations for continuous variables. These characteristics were computed for the total patient group and stratified by AAA remodeling at one-year after EVAR.

Because of the large sample size (>40), the central limit theorem is invoked to use parametric tests to identify significant differences between the shrinkage and stable groups [20]. Categorical variables were compared using the $\chi^{2}$-test and continuous variables were compared using unpaired Student's $t$-test.

To identify predictors of AAA sac shrinkage after EVAR, univariate analysis was performed based on a binary logistic regression model. All variables with a $p$-value $<0.3$ were evaluated for inclusion in multivariable logistic regression analysis with the Enter method. The maximum number of variables that could be included in the multivariable logistic regression model was limited to a minimum of 10 patients per event-defined as the smallest number of patients in one of the two groups [21]. Deciding which specific variables to include was based on the $p$-value of univariate analysis, possible collinearity, and expectations of the predictive value. For the resulting variables, a manual stepwise logistic regression analysis was performed - using Enter-by removing the variable with the largest $p$-value per step, until the remaining variables had a significant $p$-value. These variables were then entered in the final multivariable logistic regression analysis with the Enter method.

Freedom from death was analyzed for shrinking and stable AAA using Kaplan-Meier analysis with a corresponding log-rank test. All statistical analyses were performed with IBM SPSS Statistics for Windows, where a $p$-value $<0.05$ was considered statistically significant.

\section{Results}

A total of 174 patients were enrolled. An overview of the patient selection is given in Figure 1. One-year after EVAR, 67 patients (39\%) developed $\geq 5 \mathrm{~mm}$ sac shrinkage, and 107 patients $(62 \%)$ had a stable sac. For 145 patients, their AAA remodeling category was determined by US-US comparison (shrinkage: $55(82 \%)$, stable: $90(84 \%)$ ). The AAA remodeling category of the other 29 patients was determined by CT-CT comparison (shrinkage: $12(18 \%)$, stable: $17(16 \%))$. 


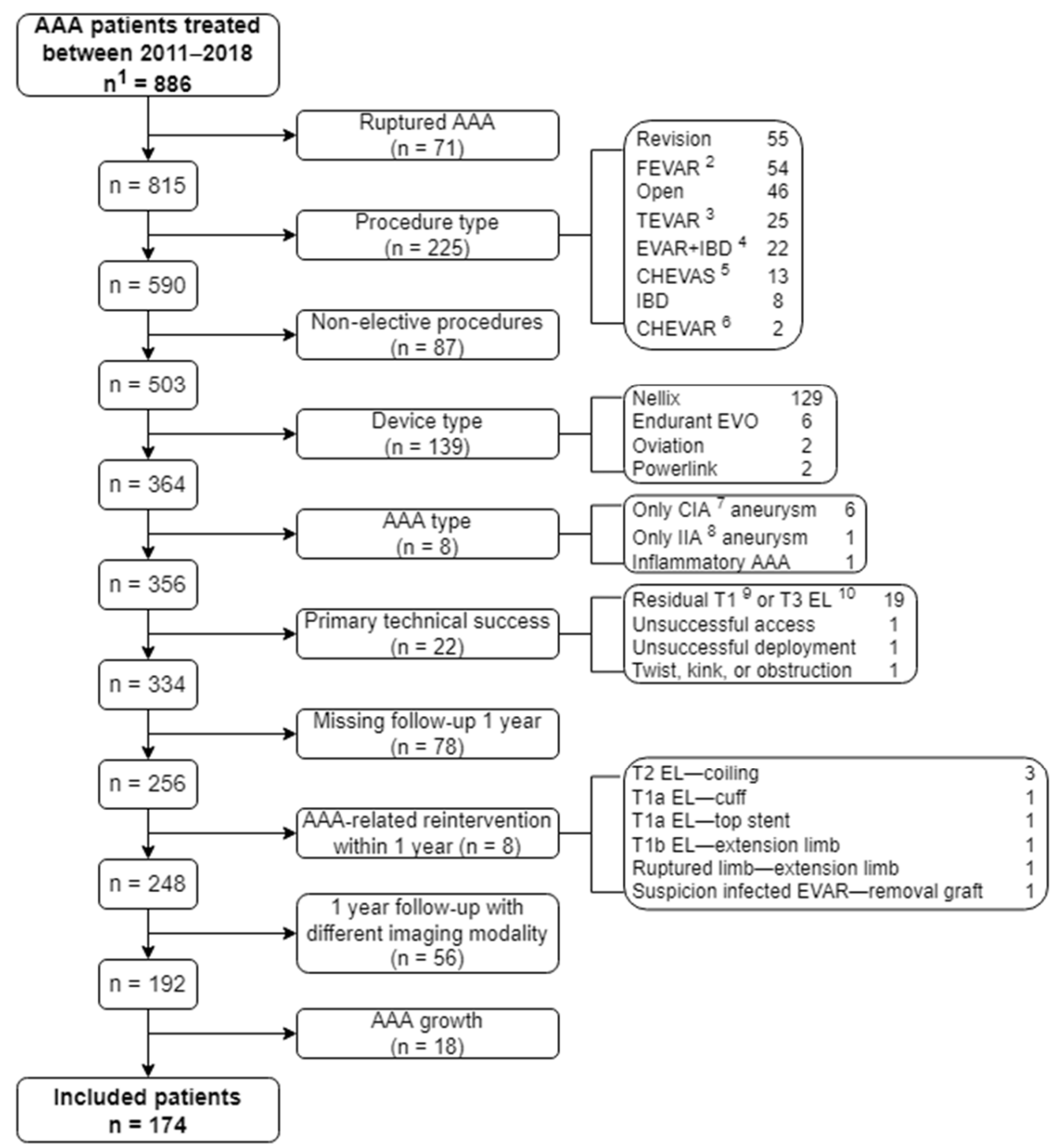

Figure 1. Flowchart of patient selection. ${ }^{1} \mathrm{n}=$ number of patients, ${ }^{2}$ FEVAR $=$ fenestrated EVAR, ${ }^{3}$ TEVAR $=$ thoracic EVAR, ${ }^{4}$ IBD $=$ iliac branched device,${ }^{5} \mathrm{CHEVAS}=$ chimney endovascular sealing, ${ }^{6} \mathrm{CHEVAR}=$ chimney EVAR, ${ }^{7} \mathrm{CIA}=$ common iliac artery, ${ }^{8} \mathrm{IIA}=$ internal iliac artery, ${ }^{9} \mathrm{~T}=$ type, ${ }^{10} \mathrm{EL}=$ endoleak.

Baseline demographics and clinical characteristics were computed for the total population, and separately for the shrinkage and stable group-as shown in Table 1. For the included patients, the mean age at the time of the procedure was 72 years (range 53-92 years), and 86\% were male. Medtronic Endurant ( $\mathrm{n}=102,59 \%)$ was the most frequently used endograft, followed by Gore Excluder $(n=51,29 \%)$, Endologix AFX ( $n=16$, $9 \%)$, Cook Zenith $(\mathrm{n}=3,2 \%)$, and Vascutek Anaconda $(\mathrm{n}=2,1 \%)$.

No significant differences were found between the two groups in terms of demographics, risk scores, atherosclerotic risk factors, comorbidities, and medication usage. The shrinkage group did show a significantly higher hemoglobin level-even though the absolute difference was only $0.2 \mathrm{mmol} / \mathrm{L}(9.1 \pm 0.8$ vs. $8.9 \pm 0.9, p=0.045)$. 
Table 1. Baseline demographics and clinical characteristics of the study population stratified by AAA shrinkage.

\begin{tabular}{|c|c|c|c|c|}
\hline Variables & $\begin{array}{c}\text { Total } \\
\text { Population }\end{array}$ & Stable & Shrinkage & $p$-Value \\
\hline Number of patients & 174 & $107(61.5)$ & $67(38.5)$ & \\
\hline Age (years) & $71.8 \pm 7.6$ & $72.6 \pm 7.3$ & $70.4 \pm 7.9$ & 0.061 \\
\hline Male sex & $149(85.6)$ & $88(82.2)$ & $61(91.0)$ & 0.107 \\
\hline $\mathrm{BMI}^{1}\left(\mathrm{~kg} / \mathrm{m}^{2}\right)$ & $26.7 \pm 3.7$ & $26.9 \pm 4.0$ & $26.4 \pm 3.1$ & 0.361 \\
\hline Systolic blood pressure (mmHg) & $142 \pm 21$ & $142 \pm 23$ & $142 \pm 20$ & 0.969 \\
\hline Diastolic blood pressure $(\mathrm{mmHg})$ & $80 \pm 10$ & $80 \pm 11$ & $81 \pm 10$ & 0.609 \\
\hline ASA $^{2}$ classification & & & & 0.734 \\
\hline 1 & $2(1.2)$ & $1(0.9)$ & $1(1.5)$ & \\
\hline 2 & $94(54.3)$ & $55(51.4)$ & $39(59.1)$ & \\
\hline 3 & $70(40.5)$ & $46(43.0)$ & $24(36.4)$ & \\
\hline 4 & $7(4)$ & $5(4.7)$ & $2(3.0)$ & \\
\hline SVS/AAVS ${ }^{3}$ risk score & $7.5 \pm 5.2$ & $7.8 \pm 5.2$ & $7.0 \pm 5.2$ & 0.383 \\
\hline SVS/AAVS risk score $0-3$ & $0.77 \pm 0.67$ & $0.81 \pm 0.68$ & $0.71 \pm 0.65$ & 0.350 \\
\hline SVS/AAVS risk score category & & & & 0.628 \\
\hline Absent & $57(36.1)$ & $34(34.0)$ & $23(39.7)$ & \\
\hline Mild & $80(50.6)$ & $51(51.0)$ & $29(50.0)$ & \\
\hline Moderate & $21(13.3)$ & $15(15.0)$ & $6(10.3)$ & \\
\hline SGVI $^{4}$ score & $3.1 \pm 0.5$ & $3.1 \pm 0.5$ & $3.0 \pm 0.5$ & 0.735 \\
\hline SGVI score high risk & $11(7.7)$ & $7(7.9)$ & $4(7.4)$ & 0.921 \\
\hline \multicolumn{5}{|l|}{ Risk factors } \\
\hline Smoking & $60(36.1)$ & $34(33.7)$ & $26(40.0)$ & 0.407 \\
\hline Diabetes mellitus & $31(17.8)$ & $17(15.9)$ & $14(20.9)$ & 0.401 \\
\hline Hypertension & $123(70.7)$ & $79(73.8)$ & $44(65.7)$ & 0.250 \\
\hline Hyperlipidemia & $134(84.3)$ & $81(82.7)$ & $53(86.9)$ & 0.476 \\
\hline Inflammatory diseases & $27(15.7)$ & $19(18.1)$ & $8(11.9)$ & 0.279 \\
\hline \multicolumn{5}{|l|}{ Comorbidities } \\
\hline Cardiac status & $77(46.7)$ & $50(48.5)$ & $27(43.5)$ & 0.533 \\
\hline Renal status & $48(27.9)$ & $31(29.2)$ & $17(25.8)$ & 0.620 \\
\hline Pulmonary status & $37(22.0)$ & $26(25.0)$ & $11(17.2)$ & 0.235 \\
\hline Coronary artery disease & $15(8.6)$ & $10(9.3)$ & $5(7.5)$ & 0.667 \\
\hline $\mathrm{COPD}^{5}$ & $29(16.7)$ & $20(18.7)$ & $9(13.4)$ & 0.365 \\
\hline \multicolumn{5}{|l|}{ Lab results } \\
\hline Hemoglobin (mmol/L) & $9.0 \pm 0.9$ & $8.9 \pm 0.9$ & $9.1 \pm 0.8$ & 0.045 \\
\hline Leukocytes $\left(\times 10^{9} / \mathrm{L}\right)$ & $8.4 \pm 2.5$ & $8.5 \pm 2.7$ & $8.2 \pm 2.0$ & 0.441 \\
\hline Creatinine $(\mu \mathrm{mol} / \mathrm{L})$ & $93 \pm 30$ & $94 \pm 32$ & $91 \pm 28$ & 0.428 \\
\hline $\operatorname{GFR}^{6}\left(\mathrm{~mL} / \mathrm{min} / 1.73 \mathrm{~m}^{2}\right)$ & $70 \pm 17$ & $69 \pm 18$ & $73 \pm 16$ & 0.094 \\
\hline \multicolumn{5}{|l|}{ Medication } \\
\hline Anticoagulant therapy & $141(84.9)$ & $87(85.3)$ & $54(84.4)$ & 0.872 \\
\hline Antiplatelet therapy & $146(83.9)$ & $86(80.4)$ & $60(89.6)$ & 0.109 \\
\hline Metformin & $26(14.9)$ & $15(14.0)$ & $11(16.4)$ & 0.666 \\
\hline Statins & $135(77.6)$ & $80(74.8)$ & $55(82.1)$ & 0.260 \\
\hline
\end{tabular}

Continuous data are presented as mean \pm standard deviation, categorical data are presented as number (\%). ${ }^{1} \mathrm{BMI}=$ body mass index, ${ }^{2} \mathrm{ASA}=$ American Society of Anesthesiologists, ${ }^{3}$ SVS $/$ AAVS = Society for Vascular Surgery/American Association for Vascular Surgery, ${ }^{4}$ SGVI $=$ St George's Vascular Institute, ${ }^{5}$ COPD $=$ chronic obstructive pulmonary disease, ${ }^{6} \mathrm{GFR}=$ glomerular filtration rate.

Preoperative AAA- and EVAR-related characteristics were also computed for the total population, and separately for the shrinkage and stable group-as shown in Table 2. No significant differences were found in terms of preoperative AAA geometry, device type, procedural characteristics, residual endoleaks, or hospitalization. 
Table 2. Baseline AAA- and EVAR-related characteristics of the study population stratified by AAA shrinkage.

\begin{tabular}{|c|c|c|c|c|}
\hline Variables & $\begin{array}{c}\text { Total } \\
\text { Population }\end{array}$ & Stable & Shrinkage & $p$-Value \\
\hline Number of patients & 174 & 107 (61.5) & $67(38.5)$ & \\
\hline \multicolumn{5}{|l|}{ Preoperative AAA ${ }^{1}$ geometry } \\
\hline Infrarenal neck diameter (mm) & $23.7 \pm 3.2$ & $23.9 \pm 3.4$ & $23.4 \pm 3.0$ & 0.395 \\
\hline Infrarenal neck length (mm) & $29.4 \pm 13.2$ & $30.0 \pm 13.6$ & $28.3 \pm 12.7$ & 0.421 \\
\hline Infrarenal $\beta$ angle $\left(^{\circ}\right)$ & $51.7 \pm 16.3$ & $53.2 \pm 16.8$ & $49.2 \pm 15.3$ & 0.121 \\
\hline Maximum AAA diameter (mm) & $54.3 \pm 8.6$ & $53.7 \pm 9.1$ & $55.3 \pm 7.6$ & 0.221 \\
\hline Maximum CIA diameter (mm) & $18.6 \pm 8.0$ & $19.1 \pm 7.9$ & $17.9 \pm 8.2$ & 0.392 \\
\hline Maximum EIA ${ }^{2}$ diameter $(\mathrm{mm})$ & $9.4 \pm 2.5$ & $9.3 \pm 2.0$ & $9.6 \pm 3.2$ & 0.449 \\
\hline Device & & & & 0.982 \\
\hline Medtronic Endurant & $102(58.6)$ & $64(59.8)$ & $38(56.7)$ & \\
\hline Gore Excluder & $51(29.3)$ & $31(29.0)$ & $20(29.9)$ & \\
\hline Endologix AFX & $16(9.2)$ & $9(8.4)$ & $7(10.4)$ & \\
\hline Cook Zenith & $3(1.7)$ & $2(1.9)$ & $1(1.5)$ & \\
\hline Vascutek Anaconda & $2(1.1)$ & $1(0.9)$ & $1(1.5)$ & \\
\hline Graft material & & & & 0.701 \\
\hline Polyester & $107(61.5)$ & $67(62.6)$ & $40(59.7)$ & \\
\hline PTFE $^{3}$ & $67(38.5)$ & $40(37.4)$ & $27(40.3)$ & \\
\hline Blood loss (mL) & $183 \pm 313$ & $177 \pm 293$ & $193 \pm 346$ & 0.746 \\
\hline Procedure time (min) & $98 \pm 45$ & $100 \pm 46$ & $95 \pm 42$ & 0.459 \\
\hline Perioperative residual endoleak & $36(20.9)$ & $22(21.0)$ & $14(20.9)$ & 0.993 \\
\hline Type I endoleak & $0(0)$ & $0(0)$ & $0(0)$ & $\mathrm{NA}^{4}$ \\
\hline Type II endoleak & $33(19.0)$ & $19(17.8)$ & $14(20.9)$ & 0.607 \\
\hline Type III endoleak & $0(0)$ & $0(0)$ & $0(0)$ & NA \\
\hline Type IV endoleak & $1(0.6)$ & $1(0.9)$ & $1(0.9)$ & 0.427 \\
\hline Days at hospital & $3.4 \pm 1.9$ & $3.6 \pm 2.0$ & $3.2 \pm 1.7$ & 0.139 \\
\hline Days at ICU ${ }^{5}$ & $0.01 \pm 0.08$ & $0.01 \pm 0.1$ & $0.00 \pm 0.00$ & 0.417 \\
\hline $\begin{array}{l}\text { Complications during } \\
\text { hospitalization }\end{array}$ & 31 (17.9) & 20 (18.9) & $11(16.4)$ & 0.682 \\
\hline
\end{tabular}

To identify predictors of AAA sac shrinkage, baseline characteristics were analyzed with univariate and multivariable logistic regression analysis-for which the main results are shown in Table 3 (all results in Table S1). On univariate analysis, no significant predictors were found.

Thirteen variables had a $p$-value $<0.3$ and were considered for inclusion in the multivariable logistic regression model, including age, gender, ASA classification, hypertension, inflammatory diseases, pulmonary history, hemoglobin level, GFR, antiplatelet therapy, statins, infrarenal $\beta$ angle, maximum AAA diameter, and days at the hospital. Only six of these variables could be included in the multivariable logistic regression analysis, as the number of events was 67. Age, hemoglobin level, and GFR had $p<0.1$ on univariate analysis and were thus included in the manual stepwise logistic regression analysis. In addition, gender, maximum AAA diameter, and infrarenal $\beta$ angle were included based on their $p$-values and expected predictive value. Based on the manual stepwise logistic regression analysis, age, infrarenal $\beta$ angle, and maximum AAA diameter were entered in the multivariable logistic regression analysis to ascertain their effects on the likelihood that patients develop a shrinking AAA.

The multivariable logistic regression model indicated that larger preoperative maximum AAA diameter was associated with an increased likelihood of developing AAA shrinkage with an OR of 1.05 (95\% CI 1.004-1.09, $p=0.031$ ), and older age at the time of procedure and larger preoperative infrarenal $\beta$ angle were associated with a reduction in the likelihood of developing AAA shrinkage with respective ORs of 0.95 (95\% CI 0.91-0.995, 
$p=0.027)$ and $0.98(95 \%$ CI $0.91-0.995, p=0.045)$. This regression model was statistically significant, $\chi^{2}(3)=11.382, p=0.010$. It explained $8.7 \%$ (Nagelkerke $\mathrm{R}^{2}$ ) of the variance in AAA remodeling and correctly classified $66.7 \%$ of the patients with AAA shrinkage from the total population.

The relation between the preoperative maximum AAA diameter and development of AAA shrinkage was further evaluated by assessing the Pearson's correlation coefficient of the preoperative maximum AAA diameter and the absolute change in AAA diameter within the first year after EVAR. The positive correlation demonstrated that in patients with a preoperative large AAA diameter, the diameter changed more than in patients with a preoperative small diameter $(\mathrm{r}=0.174, p=0.022)$.

A total of $37(21.3 \%)$ patients died after a mean of $4.7 \pm 2.2$ years after EVAR. In the shrinkage group, nine $(16.7 \%)$ patients were deceased after a mean of $5.4 \pm 2.5$ years after EVAR, and in the stable group $28(32.6 \%)$ patients were deceased after a mean of $4.5 \pm 2.1$ years (percentage: $p=0.038$, time: $p=0.309$ ). Figure 2 shows the Kaplan-Meier survival curves for shrinking and stable AAA. The log-rank test demonstrated that the survival distributions significantly differed between shrinking and stable AAA $(p=0.019)$. One EVAR-related death occurred in the stable group after 2.5 years due to an infected endograft-treated with antibiotics and open surgical removal of the endograft with insertion of a tube graft. However, postoperatively, the patient developed pneumonia and infection of the new AAA graft, which was complicated by renal insufficiency, ultimately leading to the patient's death. No EVAR-related death occurred in the shrinkage group. Other causes of death in the stable vs. shrinkage group were: neoplasm (8 vs. 1), cardiac (3 vs. 1), pulmonary ( 2 vs. 0$)$, focusless infection ( 1 vs. 0$)$, perforated diverticulitis ( 1 vs. 0$)$, renal (0 vs. 1), and unknown (12 vs. 6).

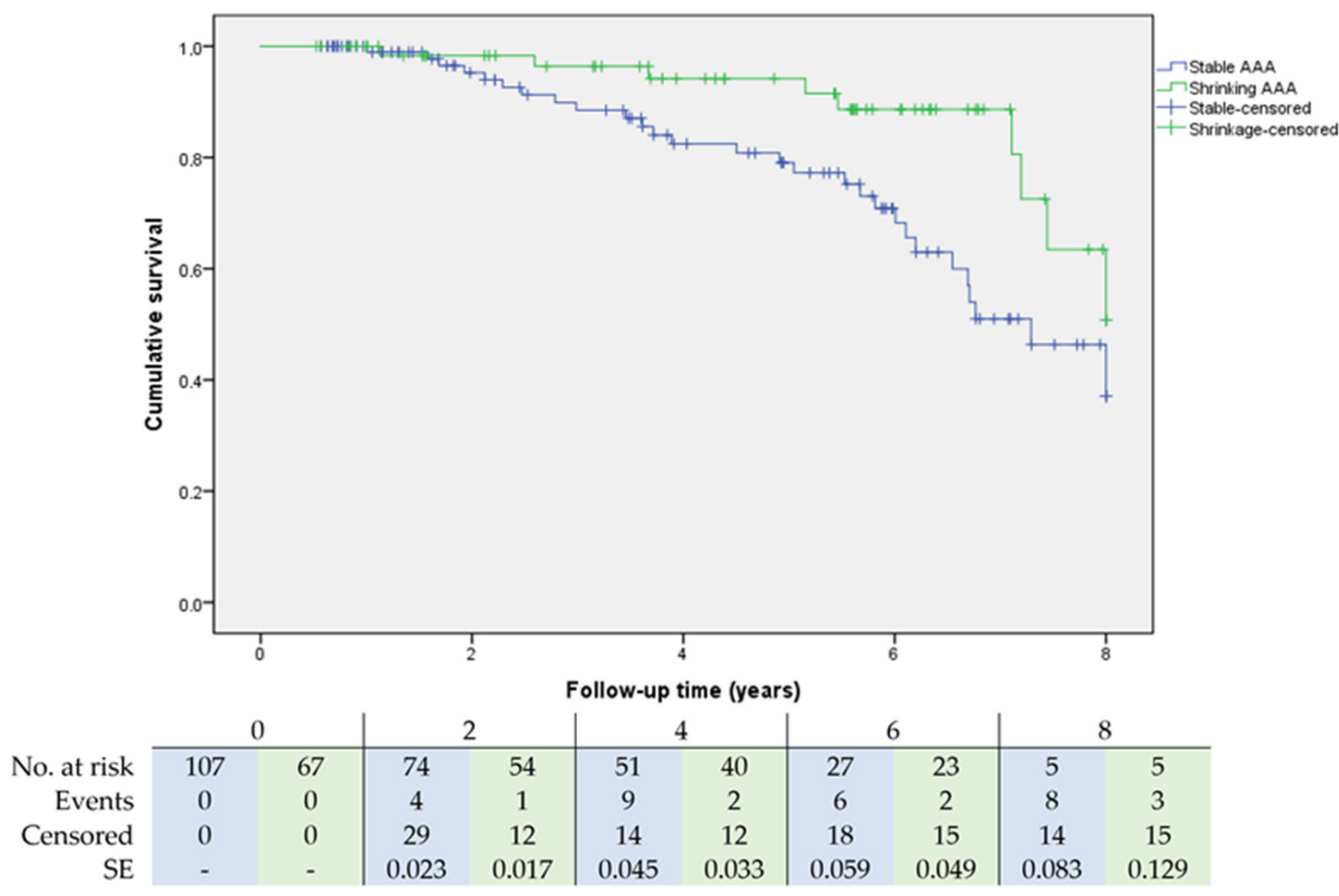

Figure 2. Kaplan-Meier survival analysis of freedom from death for stable and shrinking AAA through eight years. Number at risk represents patients at risk at that timepoint; events and censored were evaluated at end of interval. A blue color represents the stable AAA group, and a green color represents the shrinking AAA group. $\mathrm{SE}=$ standard error. 
Table 3. Logistic regression analysis of baseline characteristics for AAA sac shrinkage.

\begin{tabular}{lcccc}
\hline & \multicolumn{2}{c}{ Univariate Analysis } & \multicolumn{2}{c}{ Multivariable Analysis } \\
\cline { 2 - 5 } & OR (95\% CI) & $p$-Value & OR (95\% CI) & $p$-Value \\
\hline Age (years) & $0.96(0.92-1.00)$ & 0.063 & $0.95(0.91-0.995)$ & 0.027 \\
Male sex & $2.20(0.83-5.82)$ & 0.114 & NA & \\
Hemoglobin $(\mathrm{mmol} / \mathrm{L})$ & $1.47(1.00-2.16)$ & 0.051 & NA & \\
GFR $\left(\mathrm{mL} / \mathrm{min} / 1.73 \mathrm{~m}^{2}\right)$ & $1.02(1.00-1.04)$ & 0.096 & NA & \\
Infrarenal $\beta$ angle $\left({ }^{\circ}\right)$ & $0.99(0.97-1.00)$ & 0.122 & $0.98(0.91-0.995)$ & 0.045 \\
Maximum AAA diameter $(\mathrm{mm})$ & $1.02(0.99-1.06)$ & 0.223 & $1.05(1.004-1.09)$ & 0.031 \\
\hline
\end{tabular}

\section{Discussion}

This research showed a significantly lower all-cause mortality in patients with a shrinking AAA one-year after EVAR, compared to patients with a stable AAA, confirming data of previous studies [7-9]. In addition, one death of a patient with a stable AAA was EVAR-related, while none of the patients with AAA shrinkage died from this cause. A larger preoperative maximum AAA diameter is associated with an increased likelihood of developing AAA shrinkage one-year after EVAR-whereas older age and a larger preoperative infrarenal $\beta$ angle are associated with a reduced likelihood of AAA shrinkage. It should be noted, however, that the observed odds ratios demonstrated minor associations, and neither of these variables could independently predict AAA shrinkage on the univariate analysis. The multivariable logistic model could correctly predict two-thirds of the shrinking AAAs out of the total cohort. This indicates that the found predictors cannot be used yet in clinical care, but they do warrant attention for further research in order to be able to predict aneurysm remodeling after EVAR.

The evidence on a relationship between the preoperative AAA diameter and remodeling after EVAR varies greatly between different published studies-as shown in a recent review [13]. When focusing on studies reporting specifically on AAA remodeling oneyear after EVAR, two studies found no correlation, while two others observed that a larger preoperative AAA diameter was related to an increased likelihood of AAA shrinkage [22-25] — consistent with the findings of this analysis. However, this observation might be distorted by the focus of this study, namely comparing shrinking with stable AAA after EVAR, consequently excluding growing AAAs. If the calculation of the Pearson's coefficient between the preoperative AAA diameter and the absolute diameter change would be performed in a group with shrinking, stable, and growing AAAs $(n=192)$, it would demonstrate that a preoperative larger diameter is related to more AAA remodeling in general-so more shrinkage as well as growth $(\mathrm{r}=0.150, p=0.038)$.

Older age was found to be associated with a reduction in the likelihood of developing AAA shrinkage-similar to several other reports [26-29]. This relation might be attributed to lower elastic properties of the AAA wall in the elderly, which may contribute to the process of aortic remodeling after EVAR [30].

Another negative predictive measure for AAA shrinkage was a larger preoperative infrarenal $\beta$ angle. A recent systematic review demonstrated that two other studies that investigated AAA remodeling one-year after EVAR did not find significant relations between infrarenal angulation and AAA remodeling - in contrast to this study [13]. However, both studies were not comparable to this study as one study focused only on the Lombard Aorfix high angulation device and used another definition for neck angle [25], while the other study demonstrated smaller infrarenal angles with an undescribed measurement method of these angles [24].

When comparing this study to others, the percentages of patients presenting with a growing, stable, and shrinking AAA one-year after EVAR were comparable [11,31]. Furthermore, for the mean age, preoperative maximum AAA diameter, and incidence of type II endoleak, this cohort was comparable to other studies [12]. In addition, this sample size was similar to other single-center studies for an inclusion period of eight years [12]. 
This study also indicates some recommendations for future research to obtain more robust evidence on predictors of AAA shrinkage and its corresponding better long-term outcomes. This could also apply for other aortic segments, including the abdominal and thoracic aorta. As the findings on the predictive value of the preoperative AAA diameter are so variable, we recommend investigation of the influence of the intraluminal thrombus, luminal volume, and total AAA volume on AAA shrinkage after EVAR, as the maximum AAA diameter is composed of these volumes and they might be more sensitive in predicting AAA remodeling. Oliveira-Pinto et al. already showed that a larger AAA luminal volume is a risk factor for late complications after EVAR [32]. In addition, artificial intelligence and radiomics could be applied to improve the identification of predictors of AAA shrinkage [33,34]. Ding et al. already showed that early postoperative CT texture analysis is a better predictor of AAA growth than clinical factors and conventional imaging evaluation together [35]. In general, we emphasize the use of standardized measurement of the maximum AAA diameter before and after EVAR and encourage future studies to report the presence or absence of AAA shrinkage of $\geq 5 \mathrm{~mm}$ one-year after EVAR [7-11].

If AAA remodeling after EVAR, and the corresponding long-term outcomes, could be reliably predicted, treatment choices could be made to increase the chances of a good outcome. For instance, the decision between EVAR and open surgery could be reconsidered. Furthermore, the EVAR procedure might be optimized in selected patients with a lower likelihood of AAA shrinkage by including active sac management-such as embolization of side branches or filling the aneurysmal sac-prior to the procedure [36,37]. Reliable prediction of AAA remodeling could also aid stratification of the follow-up surveillance after EVAR based on the patient's individual risk. Currently, most surveillance programs are uniform for all patients-irrespective of the presence or absence of predictive indicators [38]. By developing risk-based surveillance programs, the burden of follow-up could be drastically reduced since $40-50 \%$ of the patients experience AAA shrinkage one-year after EVAR [7,31,39]. This would not only decrease surveillance-related costs, but also the strain and psychological burden of hospital visits on patients.

This research has several limitations. Since this is a retrospective study, it was subjected to selection and information biases. Furthermore, as a single-center study, overall generalizability of the results might be limited. To prevent confounding of predictors of AAA sac remodeling, inclusion and exclusion criteria were set more extensively than in comparable studies. Patients with non-elective procedures or AAA-related reinterventions within the first year were excluded, as well as patients without primary assisted technical success or without imaging with similar modalities pre-, and postoperatively. It is of utmost importance that, when assessing the diameter, the same imaging modality is used at each time point as this may cause an inclusion bias. A drawback of this method was that 173 patients had to be excluded because of these strict criteria. Furthermore, bias was introduced by focusing only on stable vs. shrinking AAA, while leaving out growing AAA. As a result, relations between a variable and more/less AAA remodeling might be incorrectly depicted in this study as a relation between this variable and more/less AAA shrinkage.

In conclusion, patients with a shrinking AAA, one-year after EVAR, have better longterm survival compared to patients with a stable AAA size. Preoperative age, maximum AAA diameter, and infrarenal $\beta$ angle showed to be useful in preoperatively differentiating patients that will have a shrinking AAA at one-year follow up from those with a stable AAA diameter. The final prediction model could correctly predict AAA shrinkage in twothirds of the total patients-but this is not sufficient enough to be used in clinical practice yet. Future research should therefore dive deeper into the influence of AAA anatomy on AAA shrinkage after EVAR and explore potential predictors with artificial intelligence and radiomics.

Supplementary Materials: The following are available online at https:/ / www.mdpi.com/article/ 10.3390/jcm11051394/s1, Supplementary Table S1: Logistic regression analysis of all baseline characteristics for AAA sac shrinkage. 


\begin{abstract}
Author Contributions: Conceptualization, R.E.v.R., E.G.J. and M.M.P.J.R.; methodology, R.E.v.R., S.H. and S.M.v.S.; software, R.E.v.R. and S.H.; validation, R.E.v.R.; formal analysis, R.E.v.R. and S.H.; investigation, R.E.v.R. and N.S.; resources, R.E.v.R. and S.H.; data curation, R.E.v.R.; writing—original draft preparation, R.E.v.R.; writing—review and editing, E.G.J., N.S., S.H., S.M.v.S. and M.M.P.J.R.; visualization, R.E.v.R.; supervision, E.G.J. and M.M.P.J.R.; project administration, R.E.v.R. All authors have read and agreed to the published version of the manuscript.
\end{abstract}

Funding: This research received no external funding.

Institutional Review Board Statement: The study was conducted according to the guidelines of the Declaration of Helsinki, and approved by the Institutional Review Board of Rijnstate (study number: 2021-1836, date of approval: 7 April 2021).

Informed Consent Statement: Patient consent was waived by the Institutional Review Board due to the retrospective nature of the study and the large number of patients included in the original database (>250 patients).

Data Availability Statement: The data presented in this study are available on request from the corresponding author. The data are not publicly available due to privacy reasons.

Conflicts of Interest: M.M.P.J.R. is consultant and/or received research funding from Medtronic, W.L. Gore and associates, Terumo Aortic and Jotec-Cryolife. The other authors declare no conflict of interest.

\title{
References
}

1. Albuquerque, F.C.; Tonnessen, B.H.; Noll, R.E.; Cires, G.; Kim, J.K.; Sternbergh, W.C. Paradigm shifts in the treatment of abdominal aortic aneurysm: Trends in 721 patients between 1996 and 2008. J. Vasc. Surg. 2010, 51, 1348-1352. [CrossRef]

2. Patel, R.; Sweeting, M.J.; Powell, J.T.; Greenhalgh, R.M. Endovascular versus open repair of abdominal aortic aneurysm in 15-years' follow-up of the UK endovascular aneurysm repair trial 1 (EVAR trial 1): A randomised controlled trial. Lancet 2016, 388, 2366-2374. [CrossRef]

3. Schanzer, A.; Greenberg, R.K.; Hevelone, N.; Robinson, W.P.; Eslami, M.H.; Goldberg, R.J.; Messina, L. Predictors of abdominal aortic aneurysm sac enlargement after endovascular repair. Circulation 2011, 123, 2848-2855. [CrossRef] [PubMed]

4. Walker, J.; Tucker, L.-Y.; Goodney, P.; Candell, L.; Hua, H.; Okuhn, S.; Hill, B.; Chang, R.W. Type II endoleak with or without intervention after endovascular aortic aneurysm repair does not change aneurysm-related outcomes despite sac growth. J. Vasc. Surg. 2015, 62, 551-561. [CrossRef] [PubMed]

5. $\quad$ Dijkstra, M.L.; Zeebregts, C.J.; Verhagen, H.J.M.; Teijink, J.A.W.; Power, A.H.; Bockler, D.; Peeters, P.; Riambau, V.; Becquemin, J.P.; Reijnen, M.M.P.J. Incidence, natural course, and outcome of type II endoleaks in infrarenal endovascular aneurysm repair based on the ENGAGE registry data. J. Vasc. Surg. 2020, 71, 780-789. [CrossRef] [PubMed]

6. Hwang, D.; Kim, H.-K.; Huh, S. Incidence and Risk Factors for Sac Expansion after Endovascular Aneurysm Repair of Abdominal Aortic Aneurysms. Vasc. Spec. Int. 2021, 37. [CrossRef] [PubMed]

7. O'Donnell, T.F.X.; Deery, S.E.; Boitano, L.T.; Siracuse, J.J.; Schermerhorn, M.L.; Scali, S.T.; Schanzer, A.; Lancaster, R.T.; Patel, V.I. Aneurysm sac failure to regress after endovascular aneurysm repair is associated with lower long-term survival. J. Vasc. Surg. 2019, 69, 414-422. [CrossRef]

8. Antoniou, G.A.; Alfahad, A.; Antoniou, S.A.; Torella, F. Prognostic significance of aneurysm sac shrinkage after endovascular aneurysm repair. J. Endovasc. Ther. 2020, 27, 857-868. [CrossRef]

9. Houbballah, R.; Majewski, M.; Becquemin, J.P. Significant sac retraction after endovascular aneurysm repair is a robust indicator of durable treatment success. J. Vasc. Surg. 2010, 52, 878-883. [CrossRef]

10. Bastos Gonçalves, F.; Baderkhan, H.; Verhagen, H.J.M.; Wanhainen, A.; Björck, M.; Stolker, R.J.; Hoeks, S.E.; Mani, K. Early sac shrinkage predicts a low risk of late complications after endovascular aortic aneurysm repair. Br. J. Surg. 2014, 101, 802-810. [CrossRef]

11. Plá Sánchez, F.; Martínez López, I.; Hernández Mateo, M.M.; Marqués de Marino, P.; Ucles Cabeza, O.; Baturone Blanco, A.; Serrano Hernando, F.J. Prognostic Value of Initial Aneurysmal Sac Regression after EVAR. Ann. Vasc. Surg. 2020, 64, 109-115. [CrossRef] [PubMed]

12. Lalys, F.; Daoudal, A.; Gindre, J.; Göksu, C.; Lucas, A.; Kaladji, A. Influencing factors of sac shrinkage after endovascular aneurysm repair. J. Vasc. Surg. 2017, 65, 1830-1838. [CrossRef] [PubMed]

13. van Rijswijk, R.E.; Groot Jebbink, E.; Zeebregts, C.J.A.M.; Reijnen, M.M.P.J. A systematic review on anatomical predictors of abdominal aortic aneurysm remodeling after endovascular repair. J. Vasc. Surg. 2021. [CrossRef] [PubMed]

14. Chaikof, E.L.; Blankensteijn, J.D.; Harris, P.L.; White, G.H.; Zarins, C.K.; Bernhard, V.M.; Matsumura, J.S.; May, J.; Veith, F.J.; Fillinger, M.F.; et al. Reporting standards for endovascular aortic aneurysm repair. J. Vasc. Surg. 2002, 35, 1048-1060. [CrossRef] [PubMed] 
15. Chaikof, E.L.; Fillinger, M.F.; Matsumura, J.S.; Rutherford, R.B.; White, G.H.; Blankensteijn, J.D.; Bernhard, V.M.; Harris, P.L.; Kent, K.C.; May, J.; et al. Identifying and grading factors that modify the outcome of endovascular aortic aneurysm repair. J. Vasc. Surg. 2002, 35, 1061-1066. [CrossRef]

16. Chaikof, E.L.; Dalman, R.L.; Eskandari, M.K.; Jackson, B.M.; Lee, W.A.; Mansour, M.A.; Mastracci, T.M.; Mell, M.; Murad, M.H.; Nguyen, L.L.; et al. The Society for Vascular Surgery practice guidelines on the care of patients with an abdominal aortic aneurysm. J. Vasc. Surg. 2018, 67, 2-77.e2. [CrossRef]

17. Karthikesalingam, A.; Holt, P.J.; Vidal-Diez, A.; Choke, E.C.; Patterson, B.O.; Thompson, L.J.; Ghatwary, T.; Bown, M.J.; Sayers, R.D.; Thompson, M.M. Predicting aortic complications after endovascular aneurysm repair. Br. J. Surg. 2013, 100, 1302-1311. [CrossRef]

18. Karthikesalingam, A.; Vidal-Diez, A.; De Bruin, J.L.; Thompson, M.M.; Hinchliffe, R.J.; Loftus, I.M.; Holt, P.J. International validation of a risk score for complications and reinterventions after endovascular aneurysm repair. Br. J. Surg. 2015, 102, 509-515. [CrossRef]

19. Wanhainen, A.; Bergqvist, D.; Björck, M. Measuring the Abdominal Aorta with Ultrasonography and Computed TomographyDifference and Variability. Eur. J. Vasc. Endovasc. Surg. 2002, 24, 428-434. [CrossRef]

20. Elliott, A.C.; Woodward, W.A. Statistical Analysis Quick Reference Guidebook: With SPSS Examples; Sage: Newcastle upon Tyne, UK, 2007.

21. Peduzzi, P.; Concato, J.; Kemper, E.; Holford, T.R.; Feinstein, A.R. A simulation study of the number of events per variable in logistic regression analysis. J. Clin. Epidemiol. 1996, 49, 1373-1379. [CrossRef]

22. Yeung, J.J.; Hernandez-Boussard, T.M.; Song, T.K.; Dalman, R.L.; Lee, J.T.A. Preoperative thrombus volume predicts sac regression after endovascular aneurysm repair. J. Endovasc. Ther. 2009, 16, 380-388. [CrossRef] [PubMed]

23. Nishibe, T.; Dardik, A.; Koizumi, J.; Kano, M.; Akiyama, S.; Iwahashi, T.; Kamiya, K.; Fujiyoshi, T.; Ogino, H. Simple renal cyst and its association with sac shrinkage after endovascular aneurysm repair for abdominal aortic aneurysms. J. Vasc. Surg. 2020, 71, 1890-1898.e1. [CrossRef] [PubMed]

24. Muhs, B.E.; Jordan, W.; Ouriel, K.; Rajaee, S.; de Vries, J.P. Matched cohort comparison of endovascular abdominal aortic aneurysm repair with and without EndoAnchors. J. Vasc. Surg. 2018, 67, 1699-1707. [CrossRef] [PubMed]

25. McGillicuddy, E.A.; Fillinger, M.; Robinson, W.P.; Hodgson, K.; Jordan, W.D.; Beck, A.W.; Malas, M.; Belkin, M. Lombard Aorfix high angulation device, sac behavior following implantation. J. Vasc. Surg. 2017, 66, 71-78. [CrossRef]

26. Shingaki, M.; Morishita, K.; Baba, T.; Shibata, T.; Narayama, K. Predictive Factors for Abdominal Aortic Aneurysm Shrinkage One Year after Successful Endovascular Aneurysm Repair. Ann. Vasc. Surg. 2018, 53, 92-96. [CrossRef] [PubMed]

27. Soler, R.J.; Bartoli, M.A.; Mancini, J.; Lerussi, G.; Thevenin, B.; Sarlon-Bartoli, G.; Magnan, P.E. Aneurysm sac shrinkage after endovascular repair: Predictive factors and long-term follow-up. Ann. Vasc. Surg. 2015, 29, 770-779. [CrossRef]

28. Hiraoka, A.; Chikazawa, G.; Ishida, A.; Miyake, K.; Totsugawa, T.; Tamura, K.; Sakaguchi, T.; Yoshitaka, H. Impact of age and intraluminal thrombus volume on abdominal aortic aneurysm sac enlargement after endovascular repair. Ann. Vasc. Surg. 2015, 29, 1440-1446. [CrossRef] [PubMed]

29. Boutrous, M.L.; Peterson, B.G.; Smeds, M.R. Predictors of Aneurysm Sac Shrinkage Utilizing a Global Registry. Ann. Vasc. Surg. 2021, 71, 40-47. [CrossRef]

30. Pejcic, S.; Hassan, S.M.A.; Rival, D.E.; Bisleri, G. Characterizing the mechanical properties of the aortic wall. Vessel Plus 2019, 3, 32. [CrossRef]

31. Teijink, J.A.W.; Power, A.H.; Böckler, D.; Peeters, P.; van Sterkenburg, S.; Bouwman, L.H.; Verhagen, H.J.; Bosiers, M.; Riambau, V.; Becquemin, J.P.; et al. Editor's Choice-Five Year Outcomes of the Endurant Stent Graft for Endovascular Abdominal Aortic Aneurysm Repair in the ENGAGE Registry. Eur. J. Vasc. Endovasc. Surg. 2019, 58, 175-181. [CrossRef] [PubMed]

32. Oliveira-Pinto, J.; Ferreira, R.S.; Oliveira, N.F.G.; Hoeks, S.; Van Rijn, M.J.; Raa, S.T.; Mansilha, A.; Verhagen, H.J.M.; Gonçalves, F.B. Total Luminal Volume Predicts Risk after Endovascular Aneurysm Repair. Eur. J. Vasc. Endovasc. Surg. 2020, 59, 918-927. [CrossRef] [PubMed]

33. Litjens, G.; Ciompi, F.; Wolterink, J.M.; de Vos, B.D.; Leiner, T.; Teuwen, J.; Išgum, I. State-of-the-Art Deep Learning in Cardiovascular Image Analysis. JACC Cardiovasc. Imaging 2019, 12, 1549-1565. [CrossRef] [PubMed]

34. Gillies, R.J.; Kinahan, P.E.; Hricak, H. Radiomics: Images Are More than Pictures, They Are Data. Radiology 2015, $278,563-577$. [CrossRef] [PubMed]

35. Ding, N.; Hao, Y.; Wang, Z.; Xuan, X.; Kong, L.; Xue, H.; Jin, Z. CT texture analysis predicts abdominal aortic aneurysm post-endovascular aortic aneurysm repair progression. Sci. Rep. 2020, 10, 12268. [CrossRef]

36. Hiraoka, A.; Chikazawa, G.; Ishida, A.; Totsugawa, T.; Tamura, K.; Sakaguchi, T.; Yoshitaka, H. Preoperative Coil Embolization of Side Branches and Postoperative Antifibrinolytic Therapy in Endovascular Aneurysm Repair: A Propensity Score Analysis. J. Vasc. Interv. Radiol. 2017, 28, 550-557. [CrossRef] [PubMed]

37. Branzan, D.; Geisler, A.; Steiner, S.; Doss, M.; Matschuck, M.; Scheinert, D.; Schmidt, A. Type II endoleak and aortic aneurysm sac shrinkage after preemptive embolization of aneurysm sac side branches. J. Vasc. Surg. 2021, 73, 1973-1979.e1. [CrossRef] [PubMed] 
38. Wanhainen, A.; Verzini, F.; Van Herzeele, I.; Allaire, E.; Bown, M.; Cohnert, T.; Dick, F.; van Herwaarden, J.; Karkos, C.; Koelemay, M.; et al. Editor's choice-European Society for Vascular Surgery (ESVS) 2019 clinical practice guidelines on the management of abdominal aorto-iliac artery aneurysms. Eur. J. Vasc. Endovasc. Surg. 2019, 57, 8-93. [CrossRef] [PubMed]

39. Deery, S.E.; Ergul, E.A.; Schermerhorn, M.L.; Siracuse, J.J.; Schanzer, A.; Goodney, P.P.; Cambria, R.P.; Patel, V.I. Aneurysm sac expansion is independently associated with late mortality in patients treated with endovascular aneurysm repair. J. Vasc. Surg. 2018, 67, 157-164. [CrossRef] 